\title{
COMPUTER-BASED STUDY OF MCP-COUPLED ACTIVE FILTERS FOR STRUCTURES LIKE FLF, SCF, CBQ, AND LF
}

\author{
PREM BHUSHAN MITAL \\ Department of Electronics and Communication Engg., C.R.S.C.E., MURTHAL, SONEPAT- \\ 131039 (INDIA) \\ UMESH KUMAR \\ Department of Electrical Engineering, I.I.T., New Delhi-110016, INDIA \\ (Received October 15, 1993; in final form February 22, 1994)
}

This paper deals with the problem of the realization of low sensitivity narrow BP active filter implementing multiple critical pole approximation methods. Coupled active filter structures are also studied.

The position of a MCP (multiple critical pole) transfer function containing multiple poles is realized as FLF (Follow the Leader Feedback) and and remaining part as cascade. Further MCP transfer functions are combined with CBQ (Coupled Biquads), SCF (Shifted Companion Form), and LF (Leap Frog) structure.

\section{INTRODUCTION}

Several authors ${ }^{1-3}$ have contributed to the reduction of sensitivities of cascaded filter structures at the aproximating stage by reducing the critical pole $Q$ value at the expense of increasing the total degree of the approximating function. In general, the sensitivity depend on the Q-factors of the poles and the highest Q-factor will be most relevant. This method gives a more complicated network with more active and passive elements for its realization.

Premoli and Biey ${ }^{4-6}$ introduced multiple critical pole (MCP) transfer function for the approximations of the ideal low-pass filter response compared with the standard approximation (Butterworth, Chebyshev, etc.) MCP functions. This makes the realization of active filters in cascaded form simpler.

J. Tow ${ }^{7-8}$ suggested a GELF configuration to cascade general second-order blocks with feedback from the output of each section to the input of the first one. This is applicable to any voltage transfer functions, whereas the FLF is restricted to the design of symmetrical BP and BR filter.

In this paper, given first is the synthesis procedure for realization of the MCP transfer function. Then the position of the MCP transfer function containing multiple poles is realized as FLF topology and the remaining part as cascade. Further, it has been shown that the lower sensitivities of MCP transfer functions in comparison with standard approximating functions can be further decreased by applying a FLF configuration instead of cascade. 
The following three realizations for sensitivity have been compared:

a) The cascaded realization of a transfer function without MCPs.

b) The cascaded realization of the MCP transfer.

c) The multiloop realization of the MCP transfer function.

\section{MULTIPLE CRITICAL POLE FOLLOW THE LEADER FEEDBACK FILTER}

In a low-pass filter, the locations of poles in the complex frequency plane is given as follows (Fig. 1).

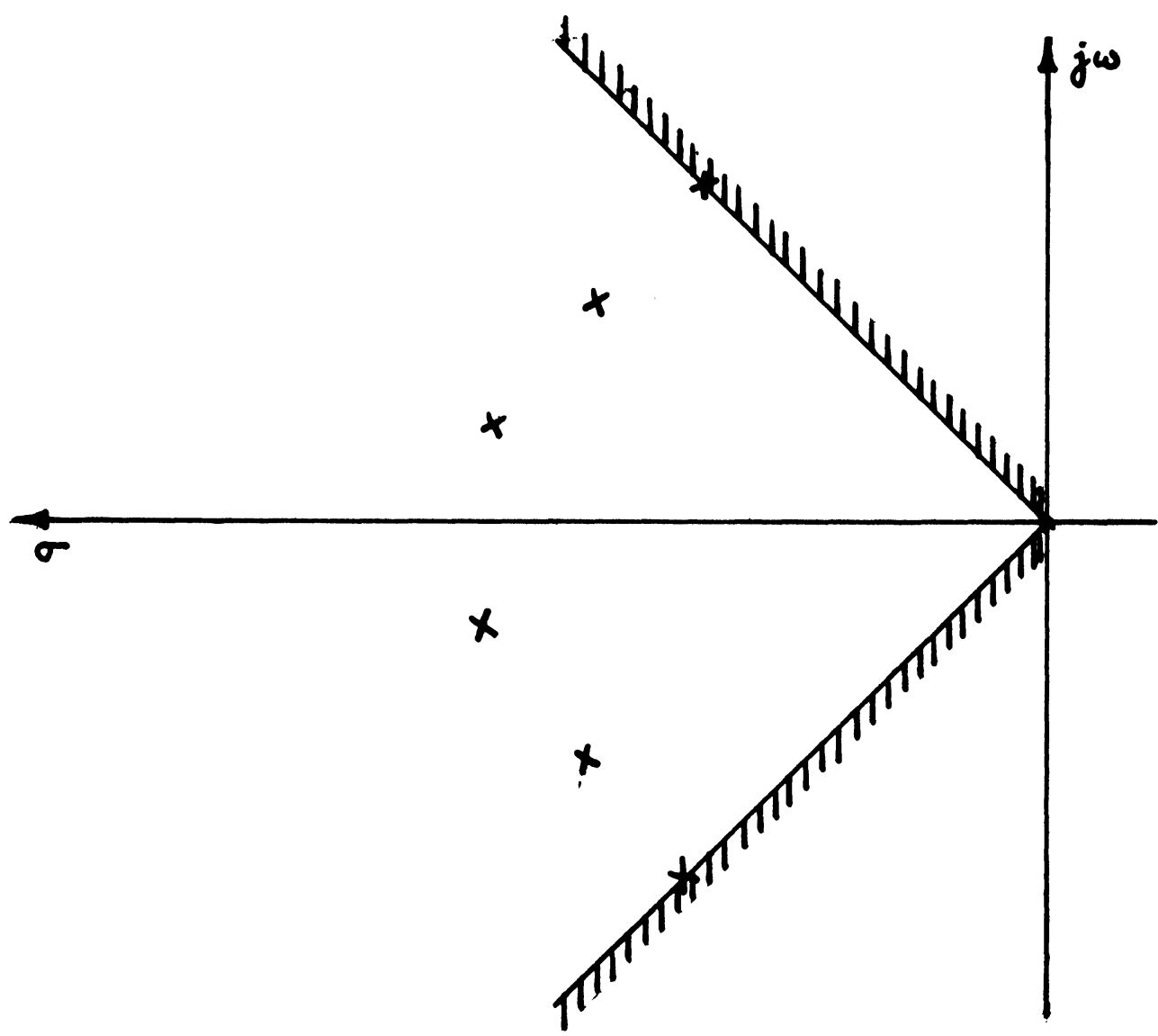

FIGURE 1 Pole locations of the corresponding MCP transfer function. 
The quality factor, $\mathrm{Q}$, of a pole can be found as follows. For a given pole location, as in Fig. 2:

$$
\mathrm{Q}_{\mathrm{i}}=\mathrm{Q}-\text { factor }=\frac{\sqrt{\mathrm{ai}^{2}+\mathrm{bi}^{2}}}{2 \mathrm{ai}}=\frac{\Omega_{\mathrm{pi}}}{2 \mathrm{ai}} \longrightarrow \mathrm{Q}_{\mathrm{i}}=\frac{1}{2 \sin \phi_{\mathrm{i}}}
$$

where $\Omega_{\mathrm{pi}}=$ pole frequency.

The pole pair closest to the jw-axis, i.e., with the highest Q-factor, is critical from sensitivity point of view of the overall transfer function.

For an nth order transfer function, the critical part can be separated out from a transfer function

$F_{n}(s)=F_{c}(s) F_{n-2}(s)$

where $F_{c}(s)$ is a second order block and $F_{n-2}(s)$ is the transfer function containing remaining poles. In Fig. 1(b), the poles of the MCP transfer function have the same pass band error specifications. When the multiplicity of the critical pole pair is introduced, the degree of the transfer function is increased by $\left(2_{m-2}\right)$, where $m$ denotes the multiplicity of the critical poles.

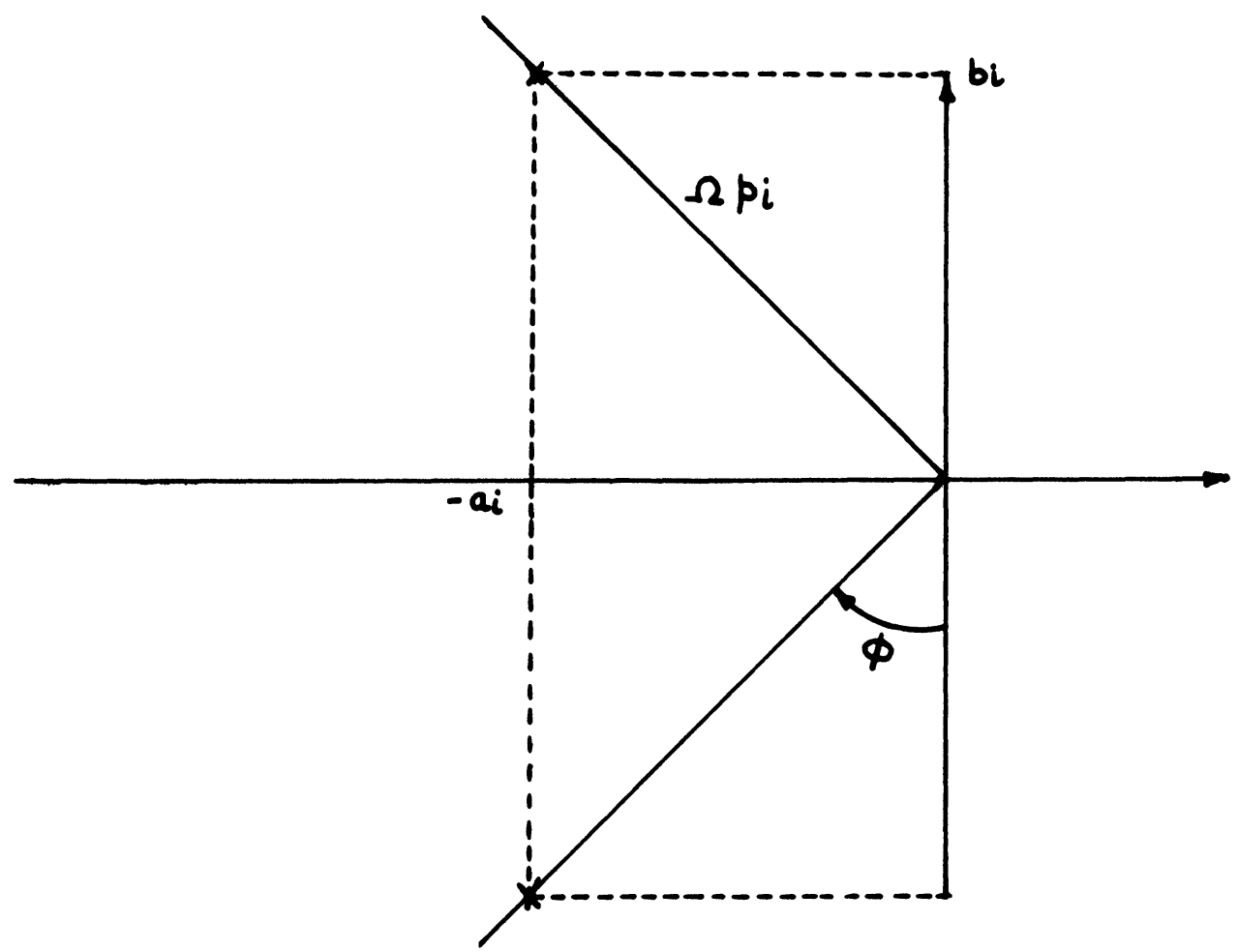

FIGURE 2 
A new transfer function can be written as

$F_{n}+2(m-1)=\left[F_{c}^{\prime}(S)\right]^{M} F_{n-2}^{\prime}(S)$

where $F_{c}^{\prime}(S)$ is the new transfer function containing the shifted critical pole pair and $F_{n-s}(S)$ is the new transfer function containing the rest of the shifted poles.

The cascaded realization of second-order blocks is considered a very attractive solution because of ease of design and tuning.

The MCP part of the BP transfer function is realized as an FLF network. Transfer function is

$$
\begin{aligned}
& F_{m c p}(S)=\left[F^{\prime}(S)\right]^{m}=\left[\frac{N_{c}(S)}{D_{c}(S)}\right]^{m} \\
& D_{c}(S)=S^{2}+\frac{\Omega_{p}}{Q_{p}} S+\Omega_{p}^{2}
\end{aligned}
$$

$N_{c}(S)=\Omega_{p}^{2} ; \quad \Omega_{p}=$ critical pole frequency

$$
\mathrm{Q}_{\mathrm{p}}=\text { critical pole quality factor }
$$

$\left[F_{c}(S)\right]^{m}=\left[\frac{N_{c}(S)}{\left(S^{2}+\frac{\Omega_{p}}{Q_{p}} S+\Omega_{p}^{2}\right)}\right]^{m}$

The function (2), when realized as an FLF network, will give the following diagram: (Fig. 3) $\beta_{\mathrm{m}}$

$$
\begin{aligned}
& \mathrm{V}_{0}=\beta_{0} \mathrm{~V}_{\text {in }}-\beta_{1} \mathrm{~V}_{1}-\beta_{2} \mathrm{~V}_{2} \ldots \beta_{\mathrm{m}} \mathrm{V}_{\mathrm{m}} \\
& \mathrm{V}_{1}=\mathrm{T}_{1}(\mathrm{~S}) \mathrm{V}_{0}(\mathrm{~S}) \\
& \mathrm{V}_{2}=\mathrm{T}_{2}(\mathrm{~S}) \mathrm{V}_{1}(\mathrm{~S})=\mathrm{T}_{1} \mathrm{~T}_{2} \mathrm{~V}_{0}(\mathrm{~S}) \\
& \mathrm{V}_{\text {out }}=\mathrm{T}_{1} \mathrm{~T}_{2} \ldots \mathrm{T}_{\mathrm{m}} \mathrm{V}_{0}(\mathrm{~S})
\end{aligned}
$$

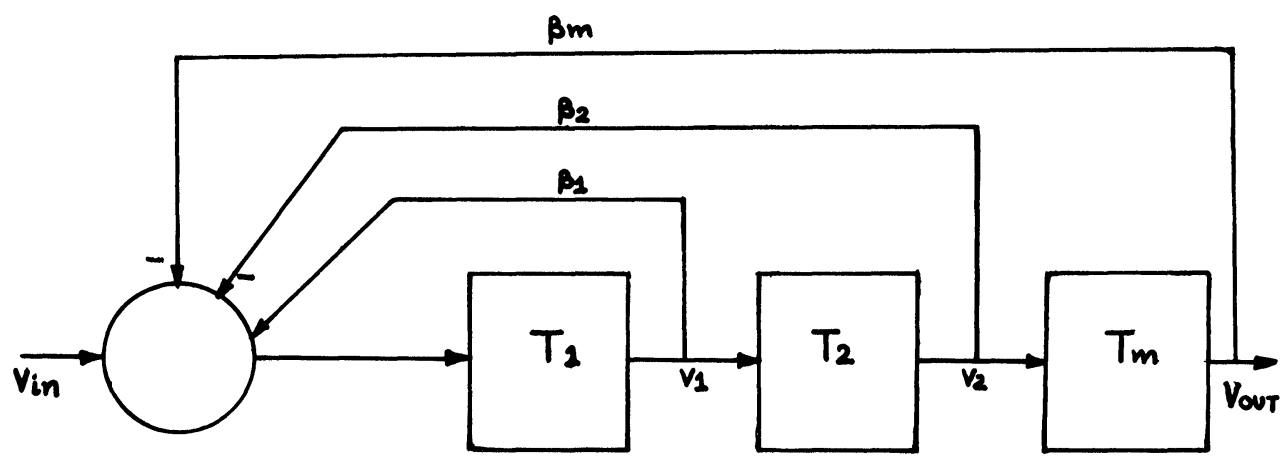

FIGURE 3 
from (3) we get

$$
\begin{aligned}
& \beta_{0} V_{\text {in }}=V_{0}+\beta_{1} V_{1}+\beta_{2} V_{2}+\ldots \beta_{m} V_{m} \\
& V_{\text {in }}=\frac{V_{0}+\beta_{1} V_{1}+\beta_{2} V_{2}+\ldots+\beta_{m} V_{m}}{\beta_{0}}
\end{aligned}
$$

New TF is

$$
\begin{aligned}
& \mathrm{F}(\mathrm{S})=\mathrm{V}_{\text {out }} / \mathrm{V}_{\text {in }} \\
& \begin{aligned}
\mathrm{F}(\mathrm{S})=\frac{\beta_{0} \mathrm{~T}_{1}(\mathrm{~S}) \mathrm{T}_{2}(\mathrm{~S}) \ldots \mathrm{T}_{\mathrm{m}}(\mathrm{S})}{1+\beta_{1} \mathrm{~T}_{1}(\mathrm{~S})+\beta_{2} \mathrm{~T}_{1}(\mathrm{~S}) \mathrm{T}_{2}(\mathrm{~S})+\ldots \beta_{\mathrm{m}} \mathrm{T}_{1}(\mathrm{~S}) \mathrm{T}_{2}(\mathrm{~S})} & \\
& =\frac{\beta_{0} \prod_{\mathrm{c}=1}^{\mathrm{m}} \mathrm{T}_{\mathrm{i}}(\mathrm{S})}{1+\sum_{\mathrm{i}=1}^{\mathrm{m}} \beta_{\mathrm{i}} \prod_{\mathrm{j}=1}^{2} \mathrm{~T}_{\mathrm{j}}(\mathrm{S})}
\end{aligned}
\end{aligned}
$$

$\beta_{\mathrm{i}}(\mathrm{i}=1,2, \ldots \mathrm{m})$ are feedback constants and $\mathrm{T}_{\mathrm{i}}(\mathrm{S})=\mathrm{K}_{\mathrm{i}} \mathrm{N}_{\mathrm{i}}(\mathrm{S}) / \mathrm{D}_{\mathrm{i}}(\mathrm{S})$ are TF of second order blocks with

$\mathrm{D}_{\mathrm{i}}(\mathrm{S})=\mathrm{S}^{2}+\frac{\Omega_{0 \mathrm{i}}}{\mathrm{Q}_{0 \mathrm{i}}} \mathrm{S}+\Omega_{0 \mathrm{i}}^{2}$

In order to retain the modularity of the cascaded approach, all the second-order blocks will be considered equal

$\mathrm{T}_{\mathrm{i}}(\mathrm{S})=\mathrm{T}(\mathrm{S})=\mathrm{KN}(\mathrm{S}) / \mathrm{D}(\mathrm{S})$

Eqn (6) can be written in the form

$$
\mathrm{F}(\mathrm{S})=\frac{\beta_{0} \mathrm{~K}\left[\frac{\mathrm{N}(\mathrm{S})}{\mathrm{D}(\mathrm{S})}\right]^{\mathrm{m}}}{\mathrm{a}+\sum_{\mathrm{i}=1}^{\mathrm{m}} \beta_{\mathrm{i}}\left[\frac{\mathrm{N}(\mathrm{S})}{\mathrm{KD}(\mathrm{S})}\right]^{\mathrm{i}}}
$$


Now $\beta_{\mathrm{i}}=\mathrm{M}_{\mathrm{C}_{\mathrm{i}}} \beta^{\mathrm{i}}$

$$
\begin{aligned}
& \mathrm{F}(\mathrm{S})=\frac{\beta_{0}\left[\frac{\mathrm{KN}(\mathrm{s})}{\mathrm{D}(\mathrm{S})}\right]^{\mathrm{m}}}{1+\sum_{\mathrm{i}=1}^{\mathrm{m}}{ }^{\mathrm{m}} \mathrm{C}_{\mathrm{i}} \beta^{\mathrm{i}}\left[\frac{\mathrm{KN}(\mathrm{S})}{\mathrm{D}(\mathrm{S})}\right]^{\mathrm{i}}} \beta_{0}\left[\frac{\mathrm{KN}(\mathrm{S})}{\mathrm{D}(\mathrm{S})}\right]^{\mathrm{m}} \\
&=\frac{{ }^{\mathrm{m}} \mathrm{C}_{0}+{ }^{\mathrm{m}} \mathrm{C}_{1} \beta^{1} \frac{\mathrm{KN}(\mathrm{S})}{\mathrm{D}(\mathrm{S})}+\frac{{ }^{\mathrm{m}} \mathrm{C}_{2} \beta^{2} \mathrm{~K}^{2} \mathrm{~N}^{2}(\mathrm{~S})}{\mathrm{D}^{2}(\mathrm{~S})}+{ }^{\mathrm{m}} \mathrm{C}_{\mathrm{m}} \frac{\beta^{\mathrm{m}} \mathrm{K}^{\mathrm{m} N^{\mathrm{m}}(\mathrm{S})}}{\mathrm{D}^{\mathrm{m}}(\mathrm{S})}}{}=\beta_{0}\left[\frac{\mathrm{KN}(\mathrm{S})}{\mathrm{D}(\mathrm{S})}\right]^{\mathrm{m}} /\left[1+\frac{\beta \mathrm{KN}(\mathrm{S})}{\mathrm{D}(\mathrm{S})}\right]^{\mathrm{m}}
\end{aligned}
$$

Comparing Eqn. (2) and (10) we get

$$
\begin{aligned}
& \mathrm{N}_{\mathrm{c}}(\mathrm{S})=\mathrm{N}(\mathrm{S}) \mathrm{K}\left(\boldsymbol{\beta}_{0}\right)^{1 / \mathrm{m}} \\
& \mathrm{D}_{\mathrm{c}}(\mathrm{S})=\mathrm{D}(\mathrm{S})+\beta \mathrm{KN}(\mathrm{S})
\end{aligned}
$$

Suppose $N_{c}(S)$ is a constant. The numerator of

$\mathrm{T}(\mathrm{S})$ can be $\mathrm{N}(\mathrm{S})=\Omega^{2}$

$\mathrm{S}_{0} \mathrm{~N}_{\mathrm{c}}(\mathrm{S})=\Omega_{0}^{2} \mathrm{~K}\left(\beta_{0}\right)^{1 / \mathrm{m}}$

$D_{c}(S)=S^{2}+\frac{\Omega_{0}(S)}{Q_{0}}+\Omega_{0}^{2}+\beta K \Omega_{0}^{2}$

$D_{c}(S)=S^{2}+\frac{\Omega_{p}}{Q_{p}} S+\Omega_{p}^{2}$

Comparing eqn. (14) and (15)

$$
\begin{aligned}
& \Omega_{\mathrm{p}}^{2}=\Omega_{0}^{2}+\beta \mathrm{K} \Omega_{0}^{2} \\
& \Omega_{\mathrm{p}}=\Omega_{0}(\sqrt{1+\beta \mathrm{K}})
\end{aligned}
$$

Now comparing eqn. (14) and (15)

$$
\Omega_{0} / Q_{0}=\Omega_{p} / Q_{p} \longrightarrow Q_{p}=\frac{\Omega_{p}}{\Omega_{0}} Q_{0}
$$


Putting $Q_{p}$ in (16) and (17)

$\mathrm{Q}_{\mathrm{p}}=\frac{\Omega_{0}(\sqrt{1+\beta \mathrm{K}})}{\Omega_{0}} \mathrm{Q}_{0}$

$\Omega_{\mathrm{p}}=\Omega_{0} \sqrt{(1+\beta \mathrm{K})}$

$\mathrm{Q}_{\mathrm{p}}=\mathrm{Q}_{0} \sqrt{(1+\beta \mathrm{K})}$

When $\beta K=0$, the FLF network becomes pure cascade and $Q_{0}(L P)=Q_{p}$. Increasing the value of $\beta \mathrm{K}$, the value of $\mathrm{Q}_{0}$ decreases. In order to maintain the modularity of two BP blocks after the LP - BP transformation, $\mathrm{Q}_{0}$ should be greater than 0.5

$0.5 \leqslant Q_{0} \leqslant Q_{p}$

\section{THE PROCEDURE FOR REALIZATION OF A BP FILTER}

Can be summarized as follows:

1. For a given BP specification, the LP prototype specifications are calculated.

2. The LP MCP is found that meets the specifications.

3. The $\mathrm{Q}_{0}$ value is chosen for individual section of the LP prototype FLF network.

4. The product $\beta \mathrm{K}$ is calculated from eqn. (20) can, putting the value of $\beta \mathrm{K}$ in (19), we calculate $\Omega_{0}$ : Between $\beta$ \& K one of them can be taken as true, which gives the value of the other.

5. The LP-BP transformation is performed on individual sections.

The resulting network has a form similar to the one in Fig. 3. The second order blocks must be replaced by fourth order BP blocks with transfer functions.

$\mathrm{T}_{1}(\mathrm{~S}) \cdot \mathrm{T}_{2}(\mathrm{~S})=\prod_{\mathrm{i}=1}^{2} \frac{\mathrm{K}_{\mathrm{i}} \mathrm{S} \mathrm{W}_{0 \mathrm{i}} / \mathrm{q}_{\mathrm{i}}}{\mathrm{S}^{2}+\frac{\mathrm{W}_{0 \mathrm{i}}}{\mathrm{q}_{\mathrm{i}}} \mathrm{S}+\mathrm{W}_{0 \mathrm{i}}^{2}}$

$\mathrm{K}_{\mathrm{i}}=$ gain constant of individual BP block. $\mathrm{W}_{0 \mathrm{i}}$ and $\mathrm{Q}_{\mathrm{i}}=$ pole frequency and pole quality factor of ith BP block.

The LP-BP transformation of each fourth-order block can be realized as a cascade of two second-order blocks with equal-quality factor if the LP-Q factor is chosen to be greater than 0.5 .

The $\mathrm{q}_{\mathrm{i}}$ 's, $\mathrm{W}_{0 \mathrm{i}}$ 's can be calculated by the LP-BP transformation formula

$\overline{\mathrm{S}}=\mathrm{S}^{2}+\mathrm{W}_{\mathrm{m}}^{2} / 2 \mathrm{BS}$.

where $\mathrm{W}_{\mathrm{m}}=$ center frequency of $\mathrm{BPF}$ and $\mathrm{B}=$ bandwidth of the BPF. 


\section{Given}

$$
\begin{aligned}
\mathrm{T}_{\mathrm{i}}(\mathrm{S})=\frac{\Omega_{0}^{2}}{\mathrm{~S}^{2}+\frac{\Omega_{0}}{\mathrm{Q}_{0}} \mathrm{~S}+\Omega_{0}^{2}} & \\
= & \frac{\Omega_{0}^{2}}{\left(\frac{\mathrm{S}^{2}+\mathrm{W}_{\mathrm{m}}}{\beta_{\mathrm{s}}}\right)^{2}+\left(\frac{\Omega_{0}}{\mathrm{Q}_{0}}\right)\left(\frac{\mathrm{S}^{2}+\mathrm{W}_{\mathrm{m}}^{2}}{\beta_{\mathrm{s}}}\right)}+\Omega_{0}^{2} \\
& =\frac{\Omega_{0}^{2} \beta^{2} \mathrm{~S}^{2}}{\mathrm{~S}^{4}+\frac{\mathrm{A}}{\mathrm{Q}_{0}} \mathrm{~S}^{3}+\left(\mathrm{A}^{2}+2 \mathrm{~W}_{\mathrm{m}}^{2}\right) \mathrm{S}^{2}+\frac{\mathrm{A}}{\mathrm{Q}_{0}} \mathrm{~W}_{\mathrm{m}}^{2} \mathrm{~S}+\mathrm{W}_{\mathrm{m}}^{4}}
\end{aligned}
$$

A second-order LP-to-BP two second-order cascade of BP will be given as

$$
\begin{aligned}
T_{1}(S) T_{2}(S)=\frac{S^{2} W_{01} W_{02} / q^{2}}{S^{4}+\frac{\left(W_{01}+W_{02}\right)}{q} S^{3}+} & \frac{\left(W_{01}^{2}+W_{02}^{2}+W_{01} W_{02}\right)}{q^{2}} S^{2} \\
& +W_{01} W_{02} \frac{\left(W_{01}+W_{02}\right)}{q} S+W_{01} W_{02}
\end{aligned}
$$

Where.

$\frac{\mathrm{W}_{01}}{\mathrm{~W}_{\mathrm{m}}}=\frac{\mathrm{W}_{\mathrm{m}}}{\mathrm{W}_{02}}$

Comparing coefficients of (21) and (22)

$$
\begin{aligned}
& \frac{W_{01}+W_{02}}{q}=A / Q_{0} \\
& W_{01}^{2}+W_{02}^{2}+\frac{W_{01} W_{02}}{q}=A^{2}+2 W_{m}^{2}
\end{aligned}
$$

from (23) and (24), it can be shown

$$
q=\left(\frac{Q_{0}}{A}\right)\left[\left(\frac{4+A^{2}+\sqrt{\left[\left(4+A^{2}\right)^{2}-4\left(A / Q_{0}\right)^{2}\right]}}{2}\right)\right]^{1 / 2}
$$


and

$\frac{W_{q}}{W_{m}}=\frac{W_{m}}{W_{02}}=\frac{q A-\sqrt{\left[(q A)^{2}-4 Q_{0}^{2}\right]}}{2 Q_{0}}$

where

$\mathrm{A}=\beta \Omega_{0} / \mathrm{W}_{\mathrm{m}}$

After determining $\mathrm{Q}_{0}$ value, the remaining problem is to maximize the signal swing within the filter. This means that the voltage maxima at all the OPAMPS outputs should be equal. The following formula is used:

$\beta_{\mathrm{i}} \prod_{\mathrm{j}=1}^{\mathrm{i}} \mathrm{Kj}=\mathrm{M}_{\mathrm{C}_{\mathrm{i}}}(\beta \mathrm{K})^{\mathrm{i}}$

The single parameter-relative sensitivity can be defined as the relative variation of a network function $\mathrm{F}$ due to small change in a component $\mathrm{X}_{\mathrm{i}}$.

$\mathrm{S}_{\mathrm{Xi}}^{\mathrm{F}}=\frac{\partial(\ln \mathrm{F})}{\partial(\ln \mathrm{Xi})}=\frac{\Delta_{\mathrm{F}} / \mathrm{F}}{\Delta_{\mathrm{Xi}} /{ }_{\mathrm{Xi}}}$

$\Delta_{\mathrm{F}} /{ }_{\mathrm{F}}=\mathrm{S}_{\mathrm{Xi}}^{\mathrm{F}} \Delta_{\mathrm{Xi}} /{ }_{\mathrm{Xi}}$

The relative change in $\mathrm{F}$ is $\Delta_{\mathrm{F}} / \mathrm{F}=\sum_{\mathrm{i}=1}^{\mathrm{N}} \mathrm{S}_{\mathrm{Xi}}^{\mathrm{F}} \Delta_{\mathrm{Xi}} /{ }_{\mathrm{Xi}} \mathrm{F}$ is a characterising function of the network such as $\mathrm{T}(\mathrm{S})$

$\Delta_{\mathrm{F}} / \mathrm{F}=\mathrm{V}_{\mathrm{Xi}}^{\mathrm{F}}=\mathrm{S}_{\mathrm{Xi}}^{\mathrm{F}} \Delta_{\mathrm{Xi}} / \mathrm{Xi}_{\mathrm{i}}$

The variation in amplitude response with respect to pole frequencies is

$\alpha(\mathrm{W})=\operatorname{Re}[\ln \mathrm{T}(\mathrm{jw})]$

$\Delta_{\alpha} / \alpha=\mathrm{V}_{\mathrm{W}_{0} \mathrm{i}}^{\alpha} \Delta_{\mathrm{W}_{(\mathrm{i})}} / \mathrm{W}_{0 \mathrm{i}} \mathrm{i}$

$\mathrm{I}=\sum_{\mathrm{i}=1}^{\mathrm{N}}\left|\mathrm{V}_{\mathrm{W}_{\mathrm{i}} \mathrm{i}}^{\alpha}\right|$

The variation in amplitude response is minimum for MUCROER FLF.

MUCROER CASCADE has less sensitivity compared to Chebyshev cascade but MUCROER CASCADE is the best so far as sensitivity is concerned.

The following example illustrates this:

a) First we consider cascade realization of an 8th order Chebyshev filter with reflection co-efficient $P=10 \%$. (Fig. 4) 


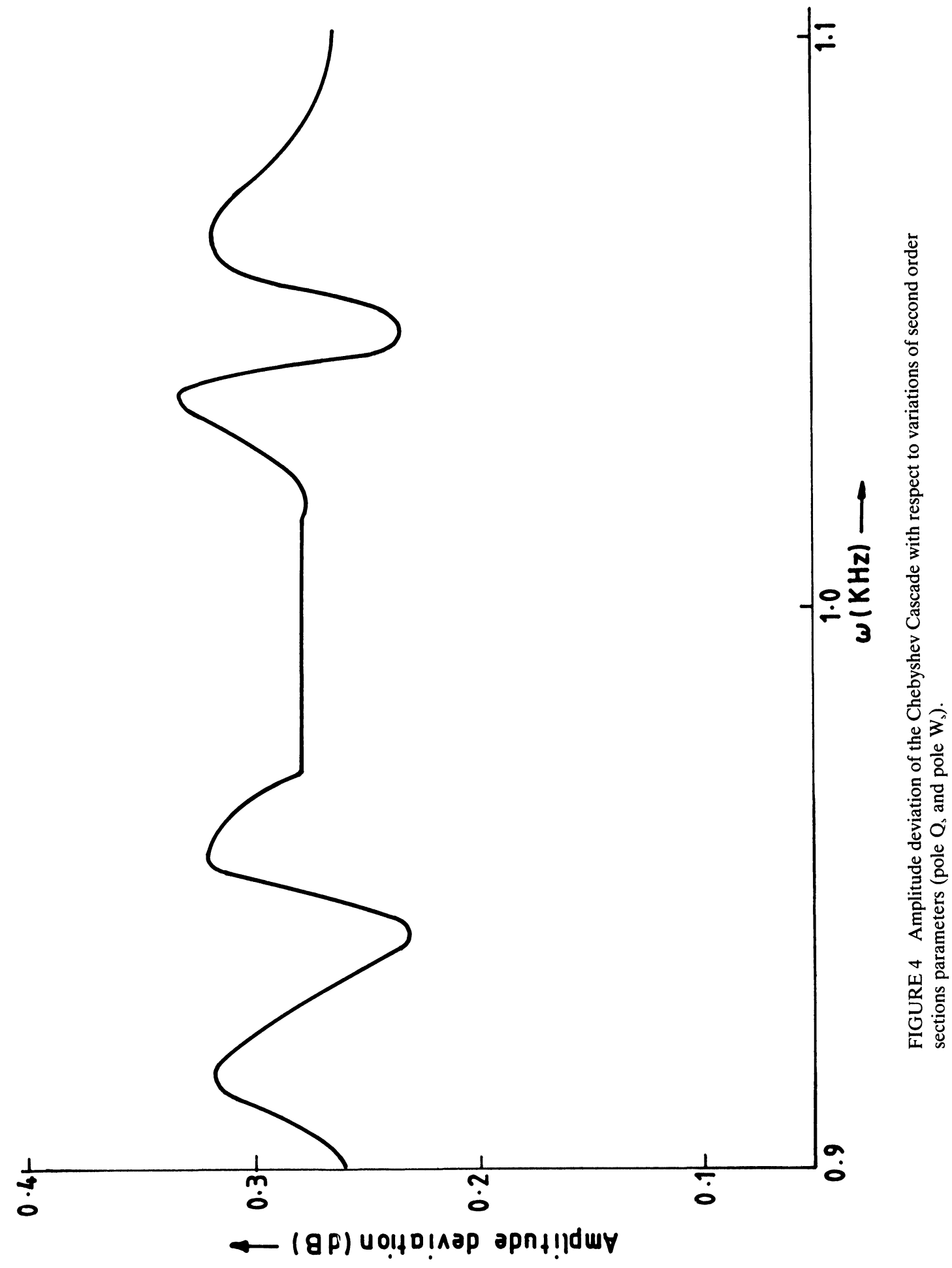


b) Next we consider realization of a 10th order MUCROER filter with $\mathrm{P}=$ $10 \%$. (Fig. 5)

c) Finally, a FLF realization of a 10th order MUCROER filter with $\mathrm{P}=10 \%$. (Fig. 6)

From the reflection co-effecient, one finds the single factor constant using the formula $P=\sqrt{t^{2} /\left(1+t^{2}\right)}$.

From this, one finds pass band and stop band attenuation. All the filters have an equal bandwidth $\mathrm{BW}=0.1$ and mid-band frequency $\mathrm{W}_{\mathrm{m}}=1$. For Chebyshev, cascade the critical pole frequency $\times \Omega_{\mathrm{pl}}=1.03$ and critical pole $\mathrm{Q}$ quality factor $=0.687=\mathrm{Q}_{\mathrm{p}_{1}}$.

First LP Block to two BP cascade for pure cascade $\beta \mathrm{K}=0(\because \beta=0)$

$\Omega_{01}=\Omega_{p_{1}}=1.03$

using eqn. (25) $Q_{01}=Q_{p_{1}}=0.687$.

$q_{i}=q_{2}=\frac{0.687}{0.103}\left[\frac{\left(4+(0.103)^{2}+\sqrt{\left[\left(4+0.103^{2}\right)^{2}-4\left(\frac{0.103}{0.687}\right)^{2}\right]}\right)}{2}\right]^{1 / 2}$ $=13.301$.

$\left(\mathrm{A}=\frac{\beta \Omega_{01}}{\mathrm{WM}}=\frac{\beta \Omega_{\mathrm{p}_{1}}}{\mathrm{WM}}=0.103\right)$

Second LP block to BP cascade

$\Omega_{12}=\Omega_{\mathrm{p}_{2}}=0.0312$

$A-0.03125, Q_{p_{2}}=0.687$

$\mathrm{q}_{3}=\mathrm{q}_{4}=31.919$

For MUCROER CASCADE

$\mathrm{q}_{2}=\mathrm{q}_{3}=\mathrm{q}_{4}=\mathrm{q}_{5}=12.737$

$q_{1}=9.4648$.

For MUCROER FLF

$\mathrm{Q}_{\mathrm{p}_{1}}=0.687$

$\Omega_{p_{1}}=1.03$ 
40

P.B. MITAL AND U. KUMAR

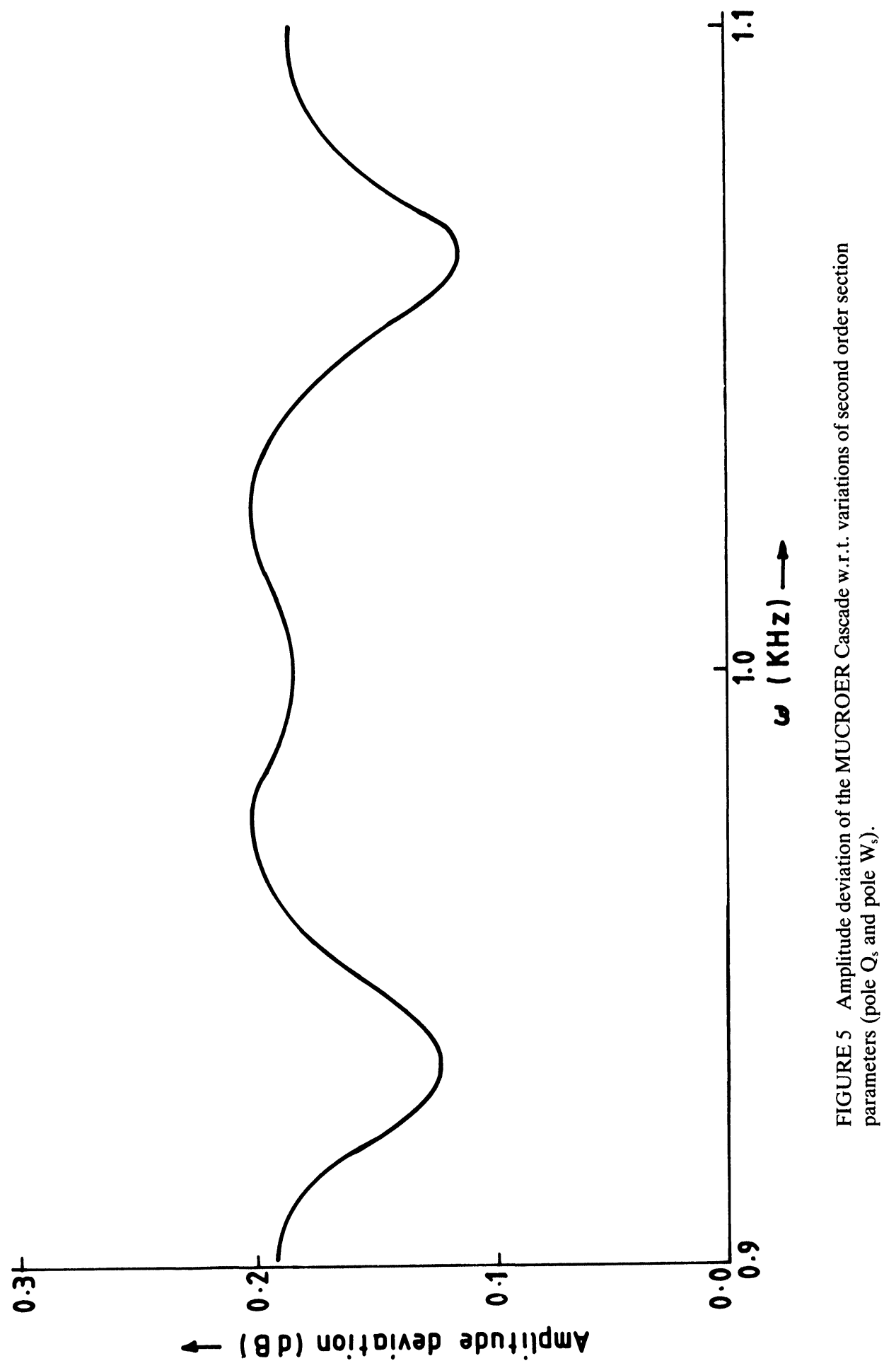




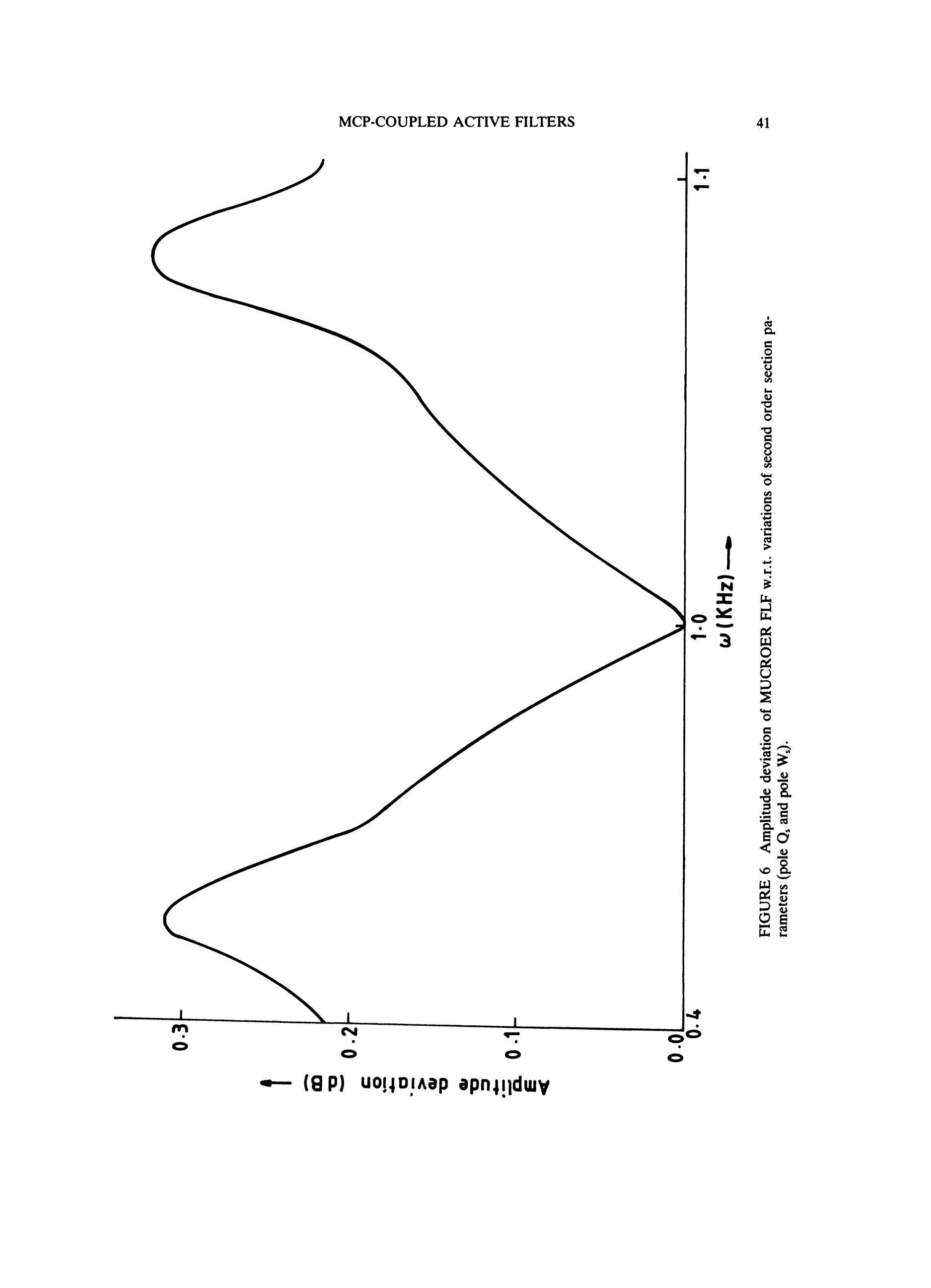


$\mathrm{Q}_{01}=0.5 ; \Omega_{01}=0.75$

$\beta \mathrm{K}=0.89$

Applying $\left.\beta \mathrm{i} \prod_{\mathrm{j}=1}^{\mathrm{i}} \mathrm{Kj}={ }^{\mathrm{M}} \mathrm{C}_{\mathrm{i}}(\beta \mathrm{K})\right)^{\mathrm{i}}$ we get $\beta_{3}=1.3376 ; \beta_{\varepsilon}=0.6616$

\section{APPLICATIONS TO THE CBQ SCF AND LF CONFIGURATIONS}

The MCP TF given in the example was tried for CBQ, SCF and LF (Fig. 5). These were compared to the corresponding 8th order Chebyshev filter realized by the same structure. The calculation for CBQ is better so far as sensitivity is concerned in stop band. For SCF realization, the sensitivity curve is almost equal to FLF case. There are slight differences within pass band, i.e., the SCF design has a little better sensitivity in a very narrow region around the center frequency, whereas FLF is better in the rest of the pass band. For both, sensitivities increase in the region outside the pass band. The CBQ design has very good sensitivity behavior in the pass band as well as in the stop band. It is much better than the cascade and somewhat better than the FLF and SCF designs. Outside the pass band, sensitivities increase but not as much as in some others. The sensitivity of LF structure is the lowest within the pass band. It has also the lowest ripple in the pass band, i.e., it is almost constant in that region. At the pass band edges, the sensitivity increases.

\section{COMPUTER BASED STUDY OF COUPLED ACTIVE FILTERS FOR STRUCTURES LIKE FLF, SCF, LF AND CBQ}

The formulae for TFs for the structure shown in Fig. 4 and Fig. 5 are as follows: for Chebyshev cascade:

$T(j w)=T_{1}(j w) \cdot T_{2}(j w) \cdot T_{3}(j w) \cdot T_{4}(j w)$

MUCROERs cascade:

$T(j w)=T_{1}(j w) \cdot T_{2}(j w) \cdot T_{3}(j w) \cdot T_{4}(j w) \cdot T_{5}(j w)$

MUCROER FLF:

$$
T(j w)=\frac{T_{1}(j w) \cdot T_{2}(j w) \cdot T_{3}(j w) \cdot T_{4}(j w) \cdot T_{5}(j w)}{1+\beta_{1} T_{2}(j w) \cdot T_{3}(j w)+\beta_{2} T_{2}(j w) \cdot T_{3}(j w) \cdot T_{4}(j w) \cdot T_{5}(j w)}
$$


MUCROER SCF: (Fig. 7):

$$
\begin{aligned}
T(j w)=\frac{T_{1}(j w) T_{2}(j w) T_{3}(j w) T_{4}(j w) T_{5}(j w)}{1+T_{1}(j w) T_{2}(j w) \beta_{2}+T_{1}(j w) T_{2}(j w) T_{3}(j w) \beta_{3}} \\
+T_{1}(j w) T_{3}(j w) T_{3}(j w) T_{4}(j w) \beta_{4} \\
\quad+T_{1}(j w) T_{2}(j w) T_{3}(j w) T_{4}(j w) T_{5}(j w) \beta_{5}
\end{aligned}
$$

MUCROER CBQ: (Fig. 8):

$$
\mathrm{T}=\frac{\mathrm{T}_{1} \mathrm{~T}_{2} \mathrm{~T}_{3} \mathrm{~T}_{4} \mathrm{~T}_{5}}{1+\mathrm{T}_{2} \mathrm{~T}_{3} \beta_{1}+\mathrm{T}_{4} \mathrm{~T}_{5} \beta_{2}+\mathrm{T}_{2} \mathrm{~T}_{3} \mathrm{~T}_{4} \beta_{1} \beta_{2}}
$$

MUCROER LF: (Fig. 9):

$$
\begin{aligned}
& \mathrm{T}=\frac{\mathrm{T}_{1} \mathrm{~T}_{2} \mathrm{~T}_{3} \mathrm{~T}_{4} \mathrm{~T}_{5}}{1+\mathrm{T}_{1} \mathrm{~T}_{2} \beta_{1}+\mathrm{T}_{2} \mathrm{~T}_{3} \beta_{2}+\mathrm{T}_{3} \mathrm{~T}_{4} \beta_{3}+\mathrm{T}_{4} \mathrm{~T}_{5} \beta_{4}+\mathrm{T}_{2} \mathrm{~T}_{3} \mathrm{~T}_{4} \mathrm{~T}_{5} \beta_{2} \beta_{4}} \\
& +\mathrm{T}_{1} \mathrm{~T}_{2} \mathrm{~T}_{3} \mathrm{~T}_{4} \beta_{1} \beta_{3}+\mathrm{T}_{1} \mathrm{~T}_{2} \mathrm{~T}_{4} \mathrm{~T}_{5} \beta_{1} \beta_{4}
\end{aligned}
$$

The TF for individual second-order blocks have been calculated using the data given in tables.

From the graphs, it can be considered that the sensitivity of the MCP part of TF can be reduced implementing coupling topologies such as FLF, SCF, CBQ, and LF. It has been found that the LF structure is superior to all from the sensitivity point of view.

\section{CONCLUSION}

In Narrow BP filter realization using multiple critical-pole approximation and coupled-filter structure methods, the internal interaction between different biquads of the filter by coupling them resulted in lesser sensitivity. There is striking correspondence between pole quality factor and pole frequencies of one biquad to the other.

Introducing a multiplicity of the critical pole and then coupling each secondorder blocks of low-pass sections results in a large reduction of pole-quality factors, which resulted in not only sensitivity minimization but also further stability of the filter if Hurwitz polynomial criterion is consulted.

The cascade design of SCF, CBQ, and LF requires a little less effort than FLF structure and, even though the quality factors are not very much reduced, it still adds to sensitivity minimization. It can be concluded that once the multiple critical portion has been separated and then coupling topology is applied, sensitivity minimization results. 


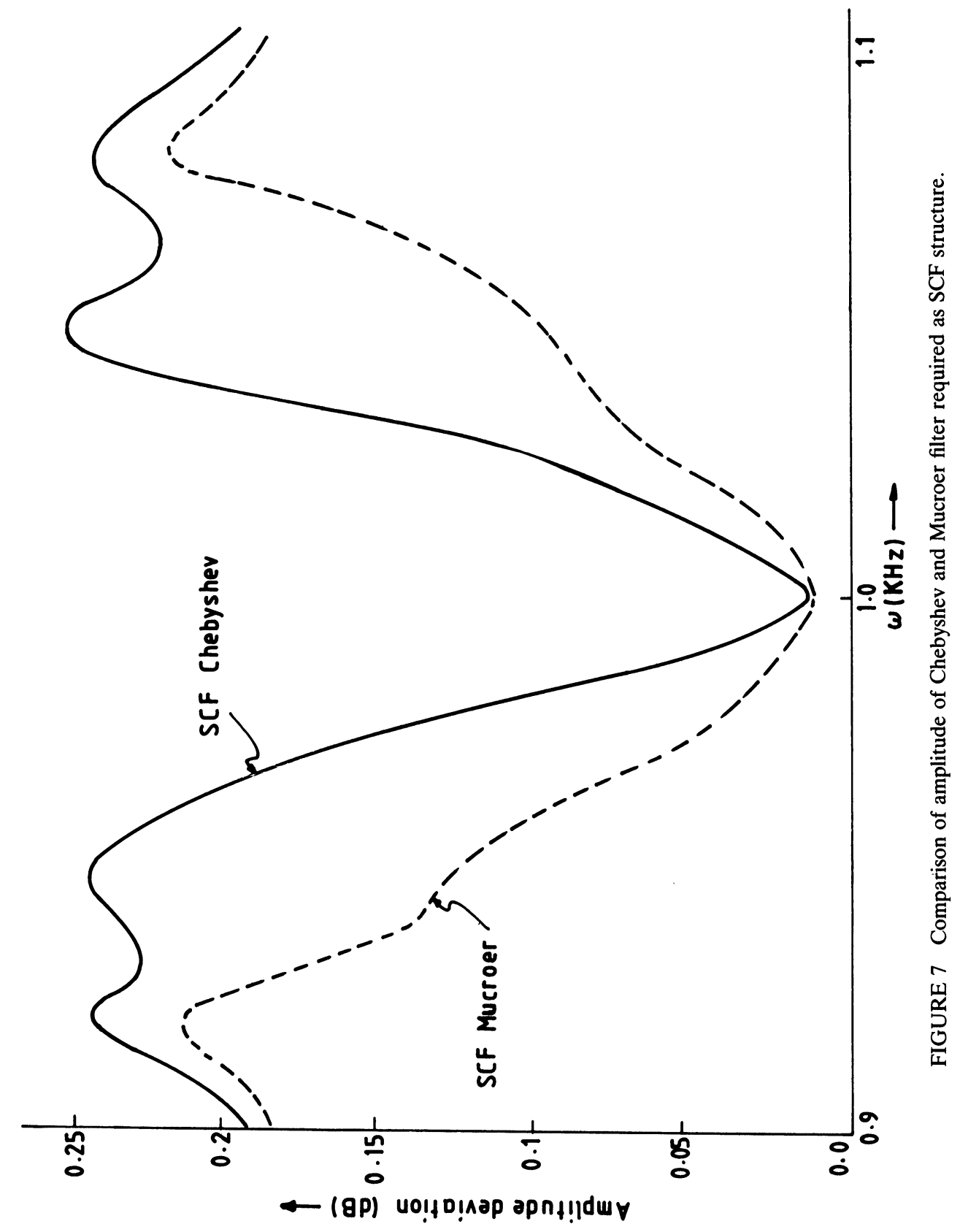




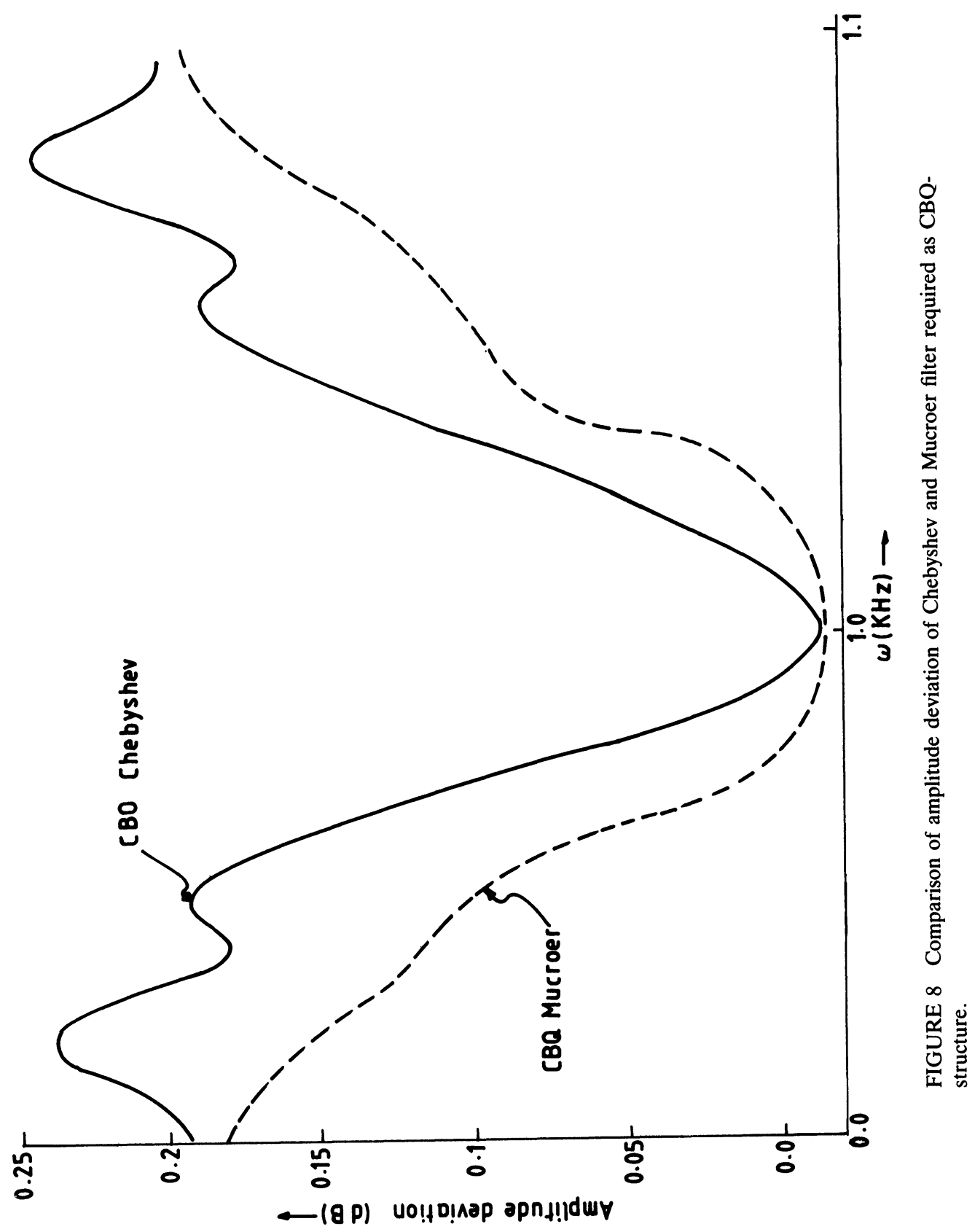




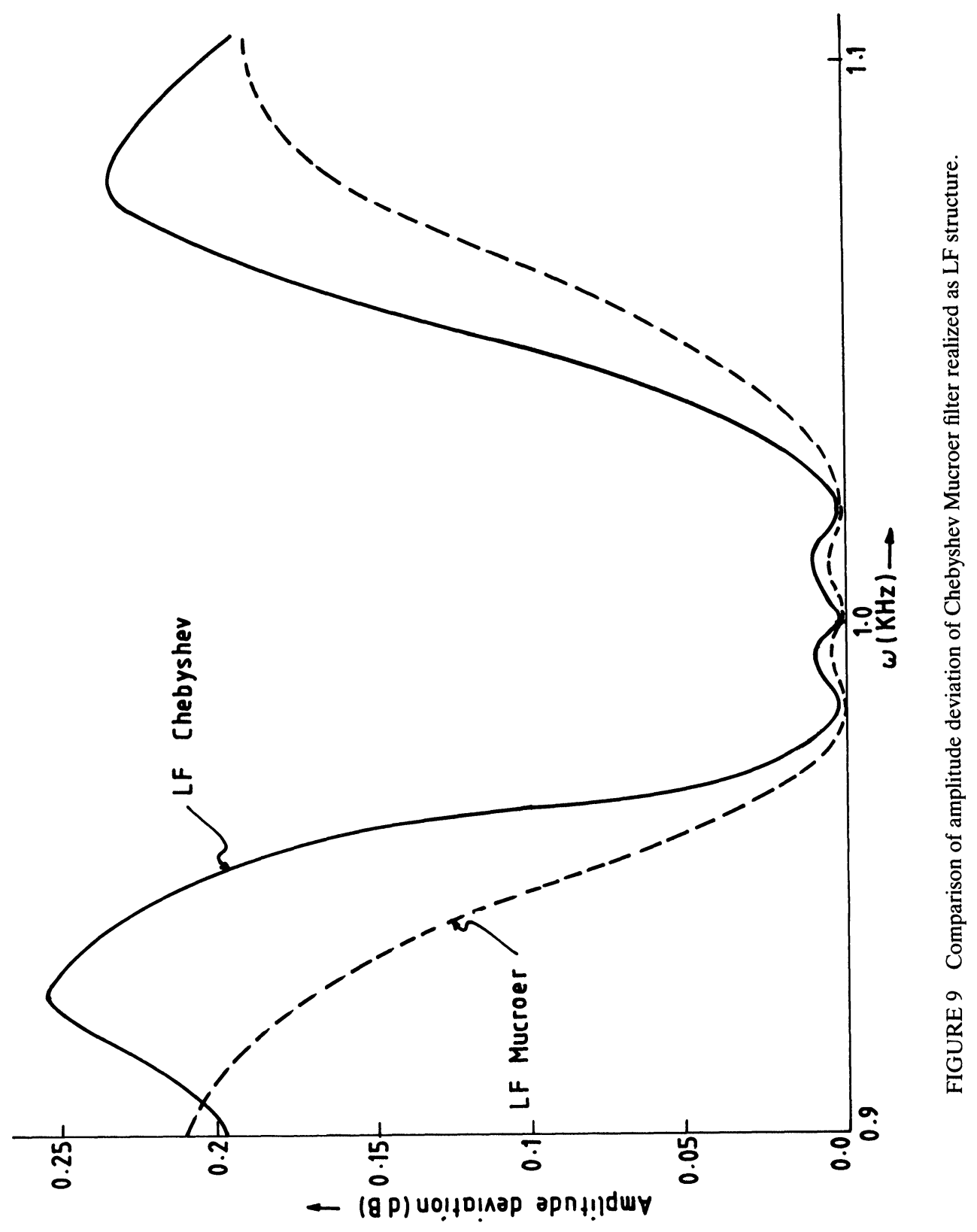


The LF structure is by far the best, but its realization is difficult. The infinite pole-Q of the second-order section is a bit of nuisance. LC prototype methods are used. RL methods are used for the rest.

CBQ structure is the simplest, but has more sensitivity compared to SCF and FLF topology.

The essential points are:

(1) Coupling topology results in reduction of pole-quality factors of individual LP prototype filters compared to those of Chebyshev filters.

(2) MUCROER examples have lower second-order section $Q$ factors compared to Chebyshev filters. CBQ, LF, and SCF configurations of MUCROER polynomial give less sensitivity within the pass band than a cascade design. CBQ is even better in stop band.

(3) The pole frequencies and quality factors are reduced by a factor of $\sqrt{(1+\beta K)}$ compared to the critical pole.

(4) This is only applicable to narrow band pass filters. So it is slightly restrictive in application.

\section{REFERENCES}

1. I.M. Filanovsky and K.A. Stromsome, "On the realization of highly selective networks by low $Q$ factor stages," IEEE Trans-circuits and systems, Vol. CAS-25, pp. 580-585, 1978.

2. G.S. Moschytz, "The sensitivity problem in active filters," scienctia Electrica, Vol. 21, pp. 81-105, 1975.

3. G.S. Moschytz, "Single amplifier active filters: A review," Scientia Electrica, Vol. 26, pp. 1-46, 1980.

4. M. Biey and A. Premoli, "Highly selective active filters using MUCROER polynomials," IEEJ. Electronic circuits \& systems, Vol. 1, pp. 155-158, 1977.

5. A. Premoli, "The MUCROMAR polynomials: an approach to the maximally flat approximation of RC-active filters with low sensitivity: IEEE Trans. circuit Theory, Vol. CT-20, 1973.

6. A. Premoli, "Tables and graphs of the MUCROER polynomials for the realization of equal ripple RC active filters with reduced sensitivity: Note recensiani Notizie, Vol. 24, pp. 399-518, 1975.

7. J. Tow, "Some results on two-section generalized active filters," IEEE trans. circuits and systems, Vol. CAS-25, pp. 181-184, 1978.

8. J. Tow, "Design and evaluation of shifted comparison from active filters, Bell system technical Journal pp. 545-568, 1975. 

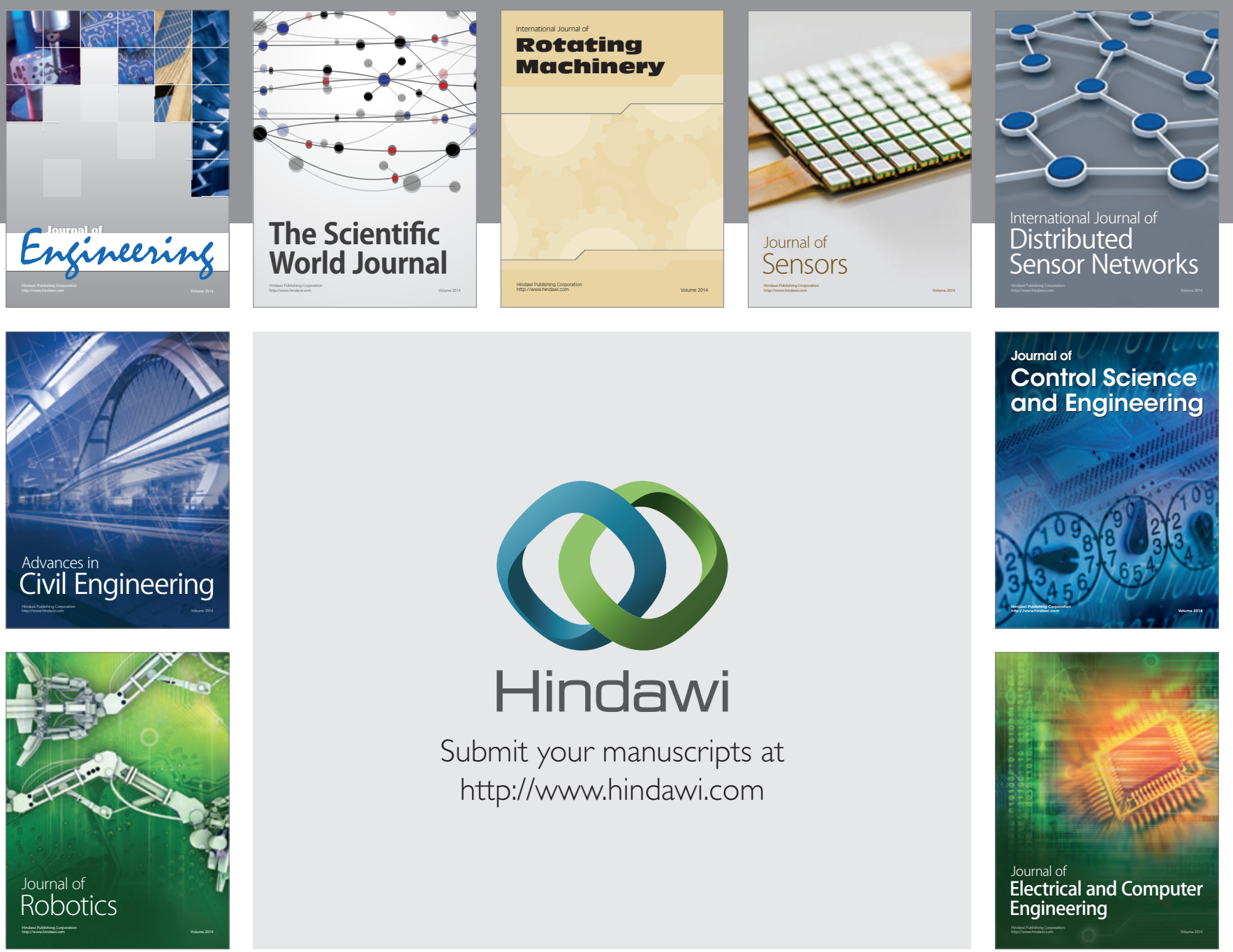

Submit your manuscripts at

http://www.hindawi.com
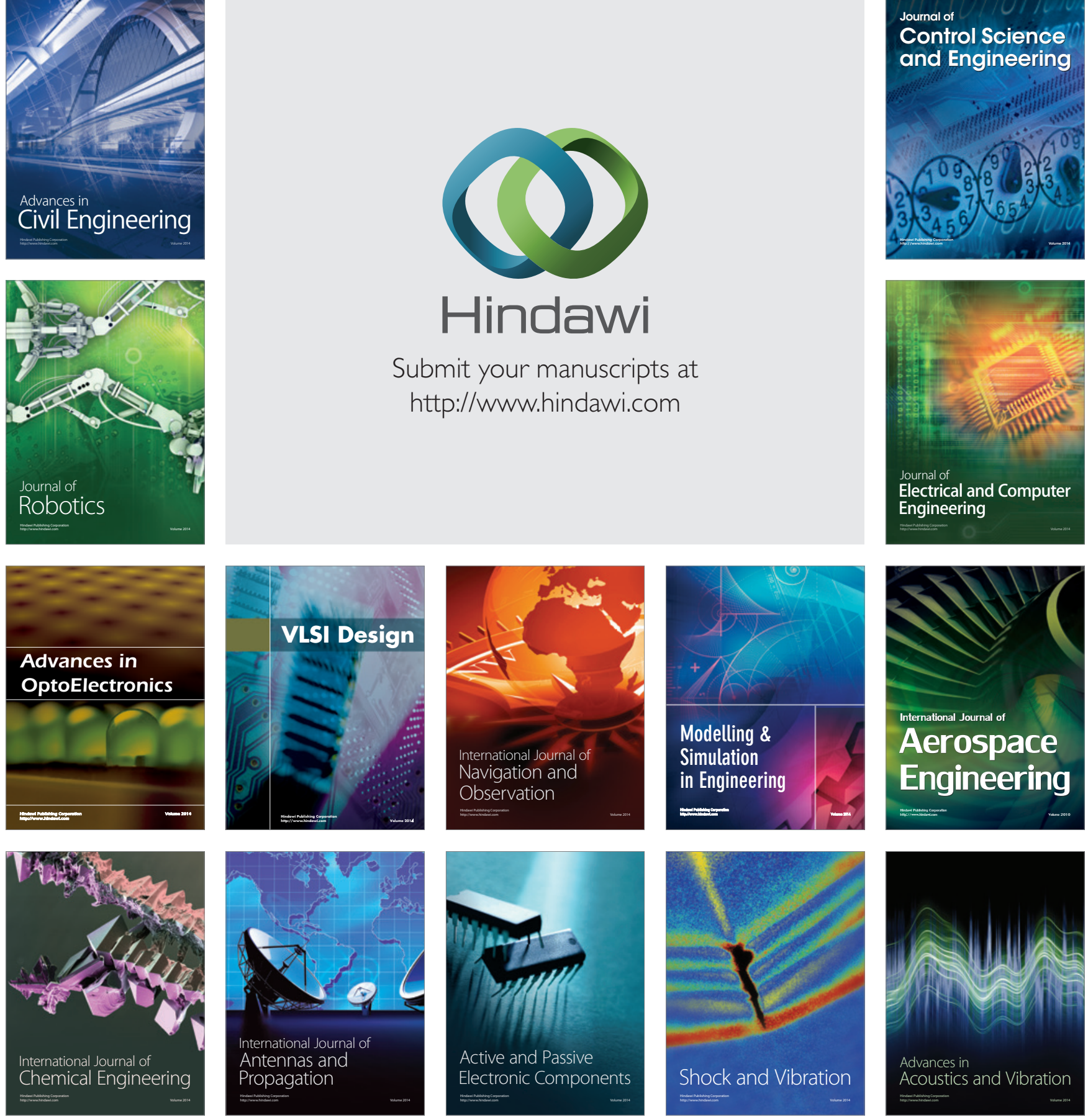